\title{
Anti-diabetic drug, metformin, and the p38 inhibitor (SB203580) reduces internal organs oxidative stress in non-obese type 2 diabetic rats
}

Nuttikarn Nokkaew ${ }^{1,2}$, Jantira Sanit ${ }^{1,2}$, Podsawee Mongkolpathumrat ${ }^{1,2}$, Siyamon Boontawee ${ }^{3}$, Supanut Ithipruchyabun ${ }^{3}$, Wannapa Plangklang ${ }^{3}$, Punyanuch Adulyaritthikul ${ }^{1,2}$, Kantapich Kongpol ${ }^{1,2}$, Sarawut Kumphune ${ }^{1,2,3 *}$

${ }^{1}$ Biomedical Research Unit in Cardiovascular Sciences (BRUCS), Faculty of Allied Health Sciences, Naresuan University, Phitsanulok 65000, Thailand. ${ }^{2}$ Graduate Program in Biomedical Sciences, Faculty of Allied Health Sciences, Naresuan University, Phitsanulok 65000, Thailand.

${ }^{3}$ Department of Medical Technology, Faculty of Allied Health Sciences, Naresuan University, Phitsanulok 65000, Thailand.

\section{ARTICLE INFO \\ Received on: 09/01/2019 \\ Accepted on: 17/04/2019 \\ Available online: 08/05/2019}

Key words:

Diabetic complications, internal organ stress, oxidative stress, protein carbonyl, metformin, p38 MAPK inhibitor.

\begin{abstract}
Diabetic complications caused by hyperglycemia and oxidative stress, which can activate $\mathrm{p} 38$ mitogen-activated protein kinase (p38 MAPK), and aggravate complications via the enhancement of reactive oxygen species (ROS) generation. Recently, metformin or p38 MAPK inhibitors could reduce ROS production in particularly protein carbonylation, in diabetic vessel. However, the combinatorial effect of metformin and SB203580 on internal organ oxidative stress in non-obese (lean) type 2 diabetes mellitus (T2DM) is still uncleared. In this study, Goto-Kakizaki rats were divided into four groups, including control diabetic group, metformin-treated group, p38 MAPK inhibitor (SB203580)-treated group, and combination between metformin and p38 MAPK inhibitor (SB203580). Internal organ protein from kidney, pancreas, liver, and brain was determined for protein carbonyl (PC) content by spectrophotometric 2, 4-Dinitrophenylhydrazine assay. There was an increase in PC content levels in the serum and internal organs of T2DM. Metformin ameliorated PC content in serum and internal organs. However, SB203580 could only reduce the PC content in the liver. The combination of metformin and SB203580 could synergistically reduce the PC content levels in serum but not the internal organs. In summary, metformin provided the greatest potential for reducing oxidative stress, while SB203580 or combined metformin with SB203580 could not reduce oxidative stress in the internal organs of non-obese type 2 diabetic rats.
\end{abstract}

\section{INTRODUCTION}

Type 2 diabetes mellitus (T2DM) progressively impairs insulin secretion by pancreatic $\beta$-cells as characterized by hyperglycemia (DeFronzo et al., 2015). Obesity was firstly associated with insulin resistance and vascular diseases (Wilcox, 2005). However, T2DM does not only occur in obese patients but can also be found in non-obese people, especially in the Asian countries (Boffetta et al., 2011; Tang et al., 2016). The severity of diabetes is primarily due to the various complications, with both

\footnotetext{
*Corresponding Author

Sarawut Kumphune, Biomedical Research Unit in Cardiovascular Sciences, Faculty of Allied Health Sciences, Naresuan University, Phitsanulok65000,Thailand.E-mail: sarawutk@nu.ac.th
}

non-obese T2DM and obese T2DM experiencing similar risks for such complications.

Diabetic vasculopathy results in disabilities and mortality in diabetic patients, such as end-stage renal failure, neuropathies, acquired blindness, and especially coronary heart disease (Yamagishi et al., 2006). These can aggravate severity and comprise a major cause of mortality among diabetic patients. Hyperglycemia also cause overproduction of reactive oxygen species (ROS), which also a major cause of vascular complications, and finally lead to cellular injury of several internal organs (Paneni et al., 2013). In addition, overproduction of ROS could also activate stress-sensitive intracellular signaling pathways, such as p38 mitogen-activated protein kinase (p38 MAPK) (Evans et al., 2002). p38 MAPK activation could cause cellular injury and death, which possibly be the cause of cellular and tissue complications 
(Kumphune et al., 2012). It has been reported that the activation of p38 MAPK during insulin resistance or T2DM was partly due to the ROS generation (Kumphune et al., 2012), which cause a reduction of glucose transporter 4 expression in adipocytes (Carlson et al., 2003). On the other hand, p38 MAPK could also regulate ROS generation, which so so-called a "feed-forward loop" (Evans et al., 2002), which could consequently induce complications. Therefore, treatment with anti-diabetic drugs or p38 MAPK inhibitor could potentially reduce ROS production and reduce the risks for diabetic complications.

Carbonylation is an oxidative modification of protein and has potential as an oxidative stress biomarker (Suzuki et al., 2010). Carbonyl stress involves the accumulation of reactive carbonylated species that result in protein malfunctions as well as toxicity, finally leading to apoptotic cell death (Fedorova et al., 2014) and diabetic complications in a variety of internal organs (Wilcox, 2005). Therefore, reduction of glycemic stress by anti-diabetic drugs or inhibition of p38 MAPK activation by using selective small molecule inhibitor is hypothesized to enable reduction of blood sugar and ROS production that could possibly prevent diabetic complications. Recent report from our group showed that the protein carbonyl (PC) content was significantly increased in blood vessel non-obese T2DM rats. Moreover, monotherapy with either metformin or p38 MAPK inhibitor (SB203580) could significantly ameliorated oxidative stress, by reducing PC content levels (Nokkaew et al., 2019). Since diabetic vasculopathy consequently lead to other internal organ complications. However, the effect of metformin or p38 MAPK inhibitor (SB203580) treatment, as well as combination of these two compounds, on internal organ oxidative stress, by protein carbonylation, has never been investigated.

This study aims to investigate the effect of metformin, and p38 MAPK selective-ATP competitive inhibitor (SB 203580) on $\mathrm{PC}$ content level in serum and extracted protein from the tissue of internal organs in non-obese T2DM rats. In addition, the synergistic effect on PC level, by combining treatment of metformin and SB203580, was also investigated.

\section{MATERIAL AND METHODS}

\section{Experiment animals}

The animal experiments in this study were conducted according to the Guidance on the Operation of Animals (Scientific Procedures) Act 1986 and the World Health Organization Guidelines for Breeding and Care of Laboratory Animals. The experimental protocols in laboratory animal were approved by Naresuan University institutional animal ethical board (NU AE581023). All procedures were designed to minimize the pain, suffering, and distress of animals involved.

In this study, all animals was purchased from Nomura Siam International Co., Ltd. Thailand. Adult male Wistar rats or Goto-Kakizaki (GK) rats, age 6-8 weeks, were used as control non-diabetic group, and non-obese type 2 diabetic model, respectively. Animals were maintained at Centre for Animal Research, Naresuan University, under constant environmental conditions temperature $\left(22^{\circ} \mathrm{C} \pm 1^{\circ} \mathrm{C}\right)$ with and a constant 12 -hour light/dark cycle.

\section{Experimental protocol and study groups}

Both of animal in control non-diabetic group as non-obese T2DM group were measured for body weight, plasma glycemic parameters, such as determining fasting blood glucose (FBG) level, percentage of $\mathrm{HbA}_{1} \mathrm{C}$, and oral glucose tolerance test (OGTT). GK rats were divided into four groups, including a diabetic group $(n$ $=6)$, metformin treatment group $(n=6)$, p38 MAPK inhibitor treatment group $(n=6)$, and drug combination group $(n=6)$. In metformin group, rats were orally administered with $15 \mathrm{mg} / \mathrm{kg}$ bw metformin (Glucophage) twice daily. The p38 MAPK selectiveATP competitive inhibitor (SB 203580) was given $2 \mathrm{mg} / \mathrm{kg}$ bw by intraperitoneal (IP) injection, every 3 days. The drug combinatorial group, GK rats were treated metformin and SB203580 with similar dosage and frequency as in single drug-treated groups. The drug treatment duration was 4 weeks, then all rats were sacrificed and internal organs, including brain, liver, kidney, and pancreas, as well as serum were collected for further investigation.

\section{Determination of plasma glycemic parameters}

The blood sample was collected from a tail vein after 12-14 hours post-fasting. Then, FBG was measured by using a glucometer (SD GlucoNavii ${ }^{\circledR}$ G DH, SB Biosensor, Korea). Determination of $\% \mathrm{HbAlc}$ was assessed by point of care testing-Clover A1C ${ }^{\text {TM }}$ Self-analyser. Assessment of glucose tolerance test in this study was performed by the OGTT. Rats were fasted overnight before receiving D-glucose solution ( $2 \mathrm{~g} / \mathrm{kg} \mathrm{bw})$. Tail vein blood were collected prior to glucose intake and every 30 minutes after taking glucose to 2 hours. The blood glucose was measured by the glucometer.

\section{Animal euthanasia, internal organs tissue collection, and protein extraction}

Rats were euthanized by overdose injection of chemical anesthetics $100 \mathrm{mg} / \mathrm{kg}$ pentobarbital, supplemented with 150 units of heparin. The surgery was performed after the evaluation of deep anesthesia. The brains, kidneys, pancreases, and livers were isolated and washed with ice-cold phosphate-buffered saline (PBS) to remove the traces of blood and other contaminants. One hundred milligrams of tissue from each organ was isolated and then homogenized by hand homogenizer on ice. The final tissue weight per homogenization buffer $[20 \mathrm{mM}$ Tris $\mathrm{HCl} \mathrm{pH} 6.8,1$ $\mathrm{mM} \mathrm{Na}_{3} \mathrm{VO}_{4}, 5 \mathrm{mM} \mathrm{NaF}$ and protease inhibitor tables (complete)] with approximately $100 \mathrm{mg}$ tissue weight: $1 \mathrm{ml}$ of buffer. Tissue homogenate was spin down at $14,000 \mathrm{rpm}$ for 10 minutes at $4^{\circ} \mathrm{C}$. The supernatants were collected for determining PC content level.

\section{Pre-analytical quality control}

In this study, the quality control was performed by linearity assay, within-run precision assay, and between-day run precision assay. For linearity assay, the control serum (HUMATROL P) was diluted into six different concentrations (ranging from 0 to $10 \mathrm{mg} / \mathrm{ml}$ ). Determination of PC content level was performed by spectrophotometric 2, 4-Dinitrophenylhydrazine (DNPH) assay in three independent experiments. The measured PC content level were plotted against concentration of the control serum. The linear regression analysis was performed. The within-run precision assays was performed in 15 continuing reactions, whereas between-day 
precision assay was performed by determining the PC content in control serum every day for 5 days. The mean values, standard deviation, and percentage for coefficients of variance $(\% \mathrm{CV})$ was analyzed.

\section{Determination of serum-internal organ protein carbonyl levels}

The PC content in serum and internal organ extracts were determined by colorimetric DNPH assay, as described in previous study (Maneewong et al., 2011). Briefly, protein samples were diluted with PBS, and incubated with $10 \mathrm{mM}$ DNPH in $2.5 \mathrm{M} \mathrm{HCl}$. Then, the protein in mixture was precipitated by $20 \%(\mathrm{w} / \mathrm{v})$ Trichloroacetic acid (TCA). After centrifugation at $10,000 \times \mathrm{g}$ for 10 minutes at $4^{\circ} \mathrm{C}$, the resuspended pellet was precipitated again with $10 \%(\mathrm{w} / \mathrm{v})$ TCA and centrifuge as above. The protein pellet was washed with $1 \mathrm{ml}$ of ethanol: ethyl acetate (1:1), and centrifuged as above. Finally, the pellet was resuspended with $6 \mathrm{M}$ guanidine hydrochloride and the optical density (OD) was measured at $370 \mathrm{~nm}$ using control as a blank (Maneewong et al., 2011).

\section{Statistical analysis}

The statistical analysis was performed by using GraphPad Prism Version 5.00 software. Comparisons of parameters were analyzed by analysis of variance, followed when appropriate by the Tukey-Kramer test. A $p$-value $\leq 0.05$ was considered to be statistically significant.

\section{RESULTS}

\section{Validation of non-obese type 2 diabetic GK rats}

The confirmation of non-obesity was performed by measuring body weight. The results showed that the average body weight of GK rats was significantly lower than age-matched control Wistar rats $(145.8 \pm 2.216 v s .182 .1 \pm 3.980)$ (Fig. 1a). The results showed that FBG levels of GK rats was significantly higher than that of non-diabetic Wistar rats $(134.3 \pm 3.919$ vs. $81.56 \pm 4.233)$ (Fig. 1b). In addition, GK rats showed a significant higher percentages for HbA1c levels in GK rats than the control non-diabetic Wistar rats $(6.400 \% \pm 0.0971 \%$ vs. $4.075 \pm 0.0313)$ (Fig. 1c). Furthermore, GK rats showed impaired glucose tolerance, in which the blood glucose was greater than $200 \mathrm{mg} / \mathrm{dl}$ after glucose uptake for 2 hours (Fig. 1d).

\section{Effect of metformin and SB203580 on plasma glycemic parameters}

After drug treatment, the blood was collected from tail vain to measure $\mathrm{FBG}$ and $\% \mathrm{HbA} 1 \mathrm{c}$. The results showed that the FBG levels of the diabetic group were significantly higher than that of non-diabetic Wistar rats $(190.7 \pm 21.39 \mathrm{mg} / \mathrm{dl}$ vs. $90.00 \pm 3.352$ $\mathrm{mg} / \mathrm{dl})$. The FBG levels was significantly reduced in metformin or SB203580 treated groups, when compared to diabetic group (117.3 $\pm 3.604 \mathrm{mg} / \mathrm{dl}$ and $149.6 \pm 5.441 \mathrm{mg} / \mathrm{dl} v s .190 .7 \pm 21.39 \mathrm{mg} / \mathrm{dl}) . \mathrm{In}$ addition, combinatorial treatment of metformin and SB203580 also significantly reduced FBG levels, when compared to diabetic group $(119.4 \pm 3.448 \mathrm{mg} / \mathrm{dl} v s .190 .7 \pm 21.39 \mathrm{mg} / \mathrm{dl})$, as shown in Figure (a)

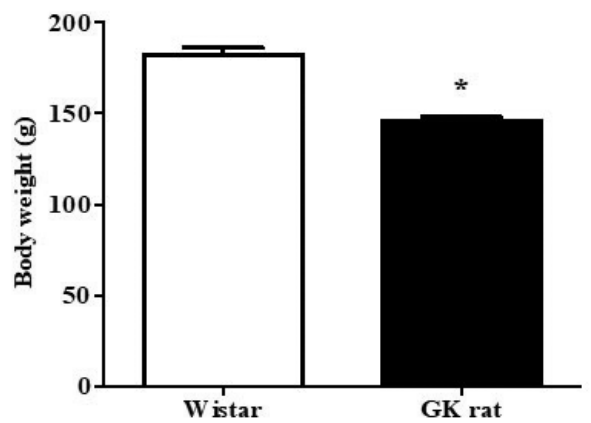

(c)

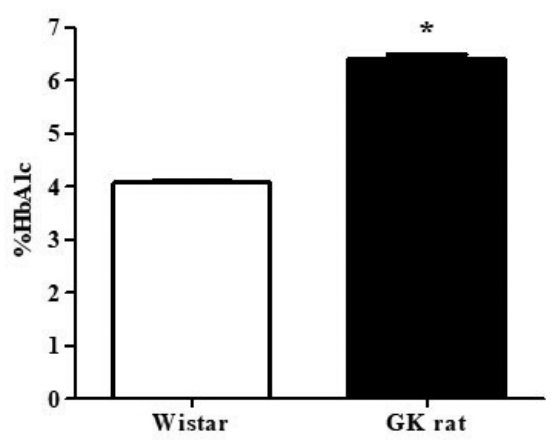

(b)

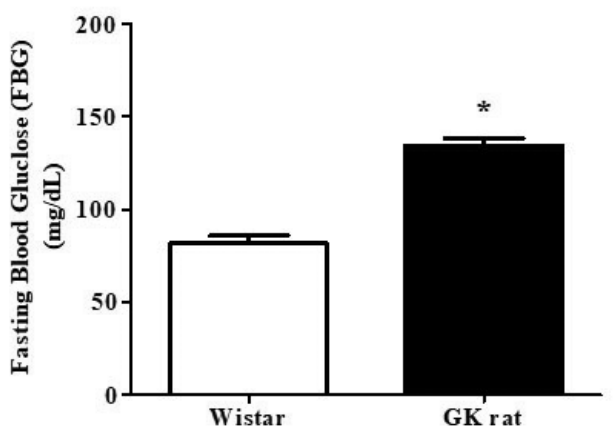

(d)

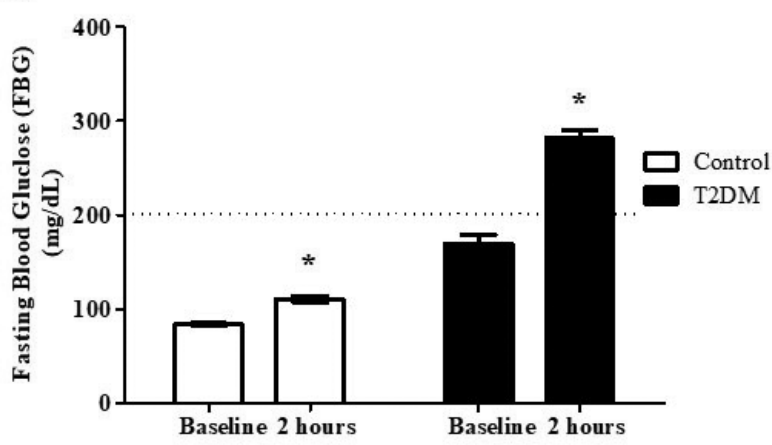

Figure 1. Validation of non-obese (lean) type 2 diabetic phenotype. The non-obese T2DM model (GK rats), used in this study, were measured for body weight (a), FBG (b), hemoglobin A1C (\%HbAlc) (c), and OGTT (d). 
2a. For Glycated haemoglobin (\%HbA1c), diabetic group showed significantly higher in $\% \mathrm{HbA} 1 \mathrm{c}$, when compared to non-diabetic Wistar rats $(6.400 \% \pm 0.09718 \%$ vs. $4.300 \% \pm 0.09258 \%)$. The level of $\% \mathrm{HbA} 1 \mathrm{c}$ was significantly reduced in metformin or SB203580 treated group, when compared to diabetic group $(5.029 \% \pm 0.1599 \%$ and $5.867 \% \pm 0.1229 \%$ vs. $6.400 \% \pm 0.09718 \%$ ). Treatment with metformin, in combination with SB203580, could significantly reduced $\% \mathrm{HbA} 1 \mathrm{c}$ compared to the diabetic group $(5.030 \pm 0.09434$ vs. $6.400 \pm 0.09718$ ) (Fig. 2b). However, no further reduction of either $\mathrm{FBG}$ or $\% \mathrm{HbA} 1 \mathrm{c}$ was apparent in the drug-combining group when compared to single-drug treatment.

\section{Pre-analytical quality control}

The linearity test showed that the methodology used in this study could provide acceptable range of linearity with $r^{2}=$ 0.9562 , and linear regression equation was $y=1.2161 x+1.4162$ (Fig. 3a). The coefficient of variation (CV) of within-run precision assay was $7.49 \%$ (Fig. 3b) and between-day precision assay was $6.13 \%$ (Fig. 3c).

(a)

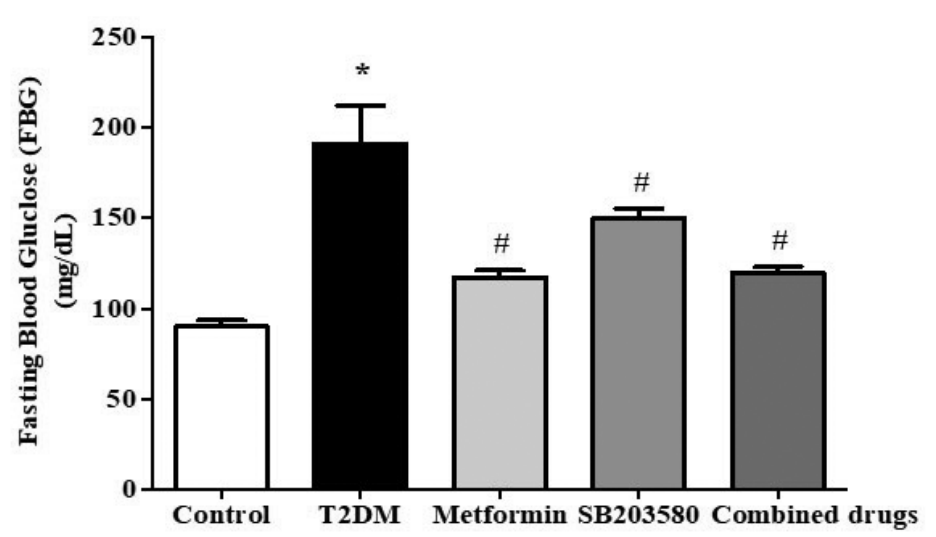

Serum protein carbonyl content levels increased in non-obese T2DM-like model, and was attenuated by treatment with metformin or SB203582

The serum PC content of diabetic group was significantly higher than that of non-diabetic control group $(8,573$ $\pm 0.3370 \mathrm{pmol} / \mathrm{mg}$ vs. $7,195 \pm 0.4232 \mathrm{pmol} / \mathrm{mgp})$. Treatment with metformin or SB203580 showed a significant decrease in serum PC content levels, when compared to the diabetic group $(7,456 \pm 0.3852 \mathrm{pmol} / \mathrm{mg}, 6,827 \pm 0.3006 \mathrm{pmol} / \mathrm{mg} v s .8,573 \pm$ $0.3370 \mathrm{pmol} / \mathrm{mg}$ ). In addition, the combination of metformin and SB203580 could significantly reduce PC content compared to that of the diabetic group $(6,104 \pm 0.2632 \mathrm{pmol} / \mathrm{mg} v s .8,573 \pm 0.3370$ $\mathrm{pmol} / \mathrm{mg}$ ). Furthermore, the synergistic effect of metformin and SB203580 was also observed to further reduce serum PC content when compared to metformin or SB203580 treatment $(6,104 \pm$ $0.2632 \mathrm{pmol} / \mathrm{mg}$ vs. $7,456 \pm 0.3852 \mathrm{pmol} / \mathrm{mg}, 6,827 \pm 0.3006$ $\mathrm{pmol} / \mathrm{mg}$ ) (Fig. 4).

(b)

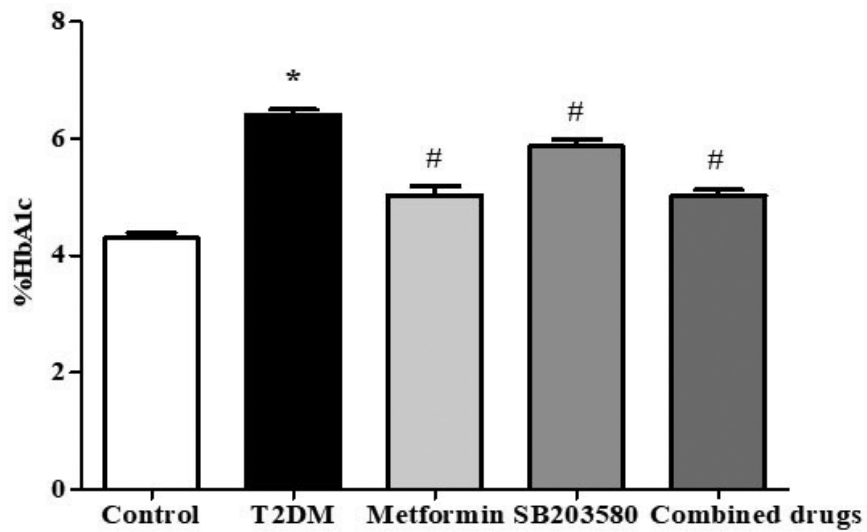

Figure 2. The combinatorial effect of metformin and SB203580 on plasma glycaemic parameters. After 4 weeks of drug treatment, blood was collected for determination of FBG (a) and HbA1c levels (b) in all experimental groups. ${ }^{*} p<0.05$ is significant between control group and T2DM group. \#p<0.05 is significant between T2DM and drug treated group.

(a)

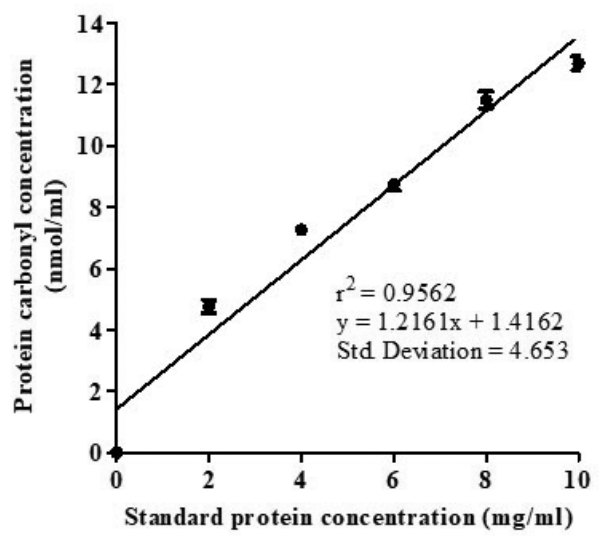

(b)

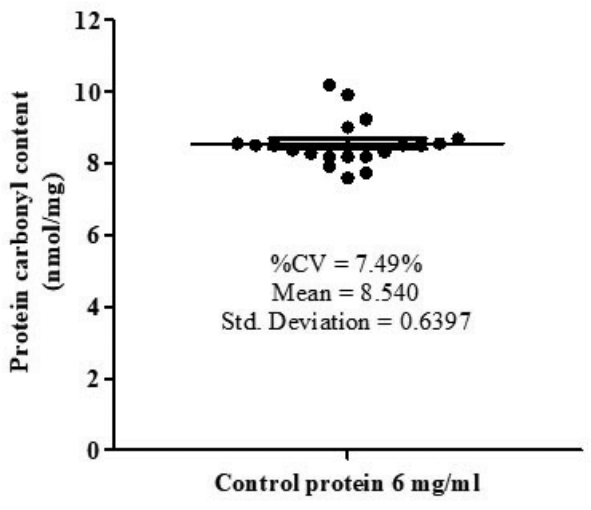

(c)

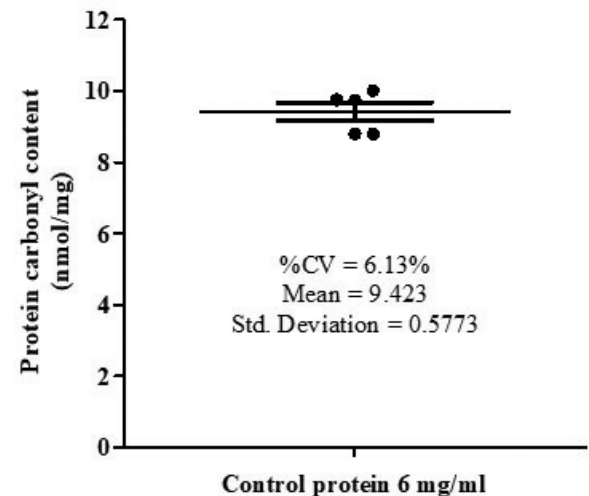

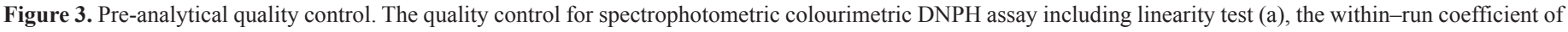
variation $(\mathrm{CV})(\mathrm{b})$, and the between-day of variation (c). 


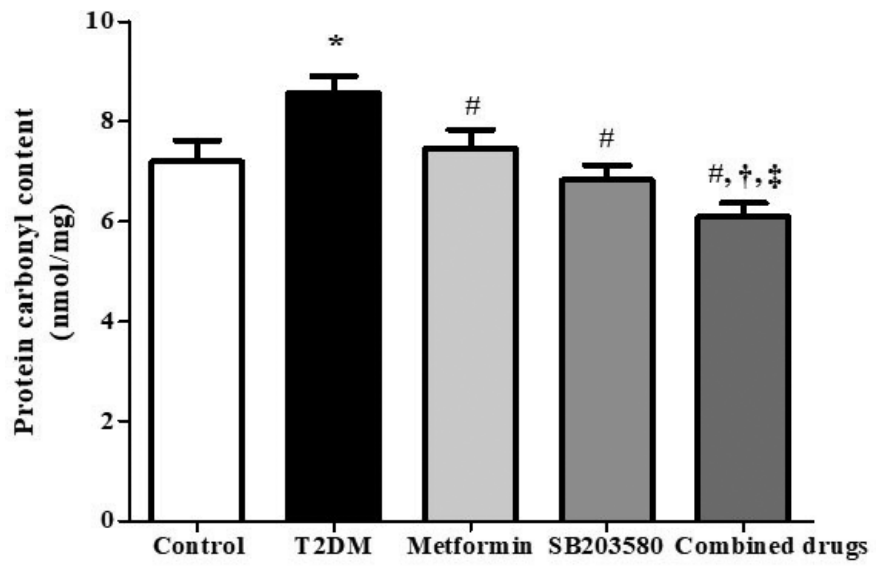

Figure 4. The combination of metformin and selective p38 MAPK inhibitor reduced PC content levels in serum of non-obese T2DM rats. After 4 weeks of drugs treatment, $\mathrm{PC}$ content in serum was analyzed by spectrophotometric DNPH assay. ${ }^{*} p<0.05$ is significant between control group and T2DM group, $\# p<0.05$ is significant between T2DM and drug treated group, $\dagger p<$ 0.05 is significant between metformin treatment and combination, $₫ p<0.05$ is significant between SB203580 treatment and combination.

\section{Metformin and SB203580 reduced internal organs protein carbonyl content levels in T2DM rats}

The measurement of PC content levels in kidney, pancreas, liver, and brain was performed by spectrophotometric DNPH assay 4 weeks after treatment in each group.

In the kidney, diabetes showed a greater level of renal PC contents than non-diabetic Wistar rats $(1,257 \pm 0.05046$ $\mathrm{pmol} / \mathrm{mg}$ vs. $1,053 \pm 0.02815 \mathrm{pmol} / \mathrm{mg})$. Also, metformin could significantly reduce renal PC content $(1,100 \pm 0.03617 \mathrm{pmol} / \mathrm{mg}$ vs. $1,257 \pm 0.05046 \mathrm{pmol} / \mathrm{mg}$ ). Single treatment of SB203580 or in combination with metformin did not provide a significant reduction of PC content levels when compared to the diabetic group $(1,186 \pm 0.05175 \mathrm{pmol} / \mathrm{mg}$ and $1,163 \pm 0.5328 \mathrm{pmol} / \mathrm{mg} v s$. $1,257 \pm 0.05046 \mathrm{pmol} / \mathrm{mg}$ ) (Fig. 5a).

In the pancreas, diabetes showed a greater level of pancreatic PC content level than non-diabetic Wistar rats $(1,552 \pm 0.1536 \mathrm{pmol} / \mathrm{mg} v s .1,166 \pm 0.03018 \mathrm{pmol} / \mathrm{mg})$. Metformin could significantly reduce pancreatic PC content levels compared to the diabetic group $(1,004 \pm 0.1381 \mathrm{pnmol} / \mathrm{mg}$ vs. $1,552 \pm 0.1536$ $\mathrm{pmol} / \mathrm{mg}$ ). There was no significant difference in pancreatic PC content in SB203580 treated group when compared to the diabetic group $(1,319 \pm 0.1074 \mathrm{pmol} / \mathrm{mg}$ vs. $1,552 \pm 0.1536 \mathrm{pmol} / \mathrm{mg})$ (Fig. 5B). The combination of metformin and SB203580 could significantly reduce PC content levels compared to the diabetic group $(1,165 \pm 0.06480 \mathrm{pmol} / \mathrm{mg}$ vs. $1,552 \pm 0.1536 \mathrm{pmol} / \mathrm{mg})$ but could not further reduce the PC content when compared to single-drug treatment.

The results from liver PC contents showed that the diabetic group had significant higher hepatic PC content when compared to non-diabetic Wistar rats $(1,645 \pm 0.05632 \mathrm{pmol} / \mathrm{mg}$ vs. $856.7 \pm 0.1021 \mathrm{pmol} / \mathrm{mgp})$. It was clearly seen that metformin or SB203580 treatment could significantly reduce the hepatic PC content levels, when compared to the diabetic group $(1,406 \pm$ $0.1227 \mathrm{pmol} / \mathrm{mg}$ and $1,409 \pm 0.06102 \mathrm{pmol} / \mathrm{mg}$ vs. $1,645 \pm 0.05632$ $\mathrm{pmol} / \mathrm{mg}$ ). The combination of metformin and SB203580 could significantly reduce PC content levels compared to the diabetic group $(1,413 \pm 0.03892 \mathrm{pmol} / \mathrm{mg} v s .1,645 \pm 0.05632 \mathrm{pmol} / \mathrm{mg})$ but could not further reduce the PC content when compared to single-drug treatment (Fig. 5c).

The results from PC content in the brain showed that PC content in the diabetic group was significantly higher than non-diabetic Wistar rats $(128.8 \pm 0.01289 \mathrm{pmol} / \mathrm{mg}$ vs. $78.02 \pm$ $0.01619 \mathrm{pmol} / \mathrm{mgp})$. Administration of metformin could reduce brain PC content greater than diabetic group $(78.56 \pm 0.01650$ $\mathrm{pmol} / \mathrm{mg}$ vs. $128.8 \pm 0.01289 \mathrm{pmol} / \mathrm{mg}, p$-value $<0.05)$. Both of SB203580 treatment or in combination with metformin could not significantly reduce brain PC content levels compared to the diabetic group $(134.1 \pm 0.004190 \mathrm{pmol} / \mathrm{mg}$ and $111 \pm 0.01258$ $\mathrm{pmol} / \mathrm{mg} v s .128 .8 \pm 0.01289 \mathrm{pmol} / \mathrm{mg}$ ) (Fig. $5 \mathrm{~d})$.

\section{DISCUSSION}

The major findings in this study reveal that the internal organs of non-obese T2DM have greater oxidative stress when compared to non-diabetic control. Treatment with anti-diabetic drugs and metformin could significantly reduce oxidative stress (PC content) both in serum and various internal organs of non-obese T2DM rats. Treatment with p38 MAPK inhibitor and SB203580 could significantly reduce FBG and glycated hemoglobin. Furthermore, treatment with SB203580 could significantly reduce oxidative stress only in the liver. The combination of metformin and SB203580 showed no significant synergistic effect in further reducing PC content only in internal organs, except serum.

Hyperglycemic conditions mainly enhance cellular respiration to produce ROS (Son, 2012). In addition, oxidative stress induces endothelial dysfunction and apoptotic cell death, leading to diabetic complications in various organs (Sasaki and Inoguchi, 2012). Previous study reported that PC level was positively correlated with homeostatic model assessment of insulin resistance, which is the parameter to indicate insulin resistance (Sarkar et al., 2010). Therefore, PC could potentially be a biomarker for assessing the risk for oxidative stress induced diabetic complications. Recently, an increasing in vascular oxidative stress, which increased vascular PC content, in non-obese T2DM rats could consequently cause oxidative stress, in internal organs of non-obese T2DM rats, which could enhance diabetic complications (Nokkaew et al., 2019). Therefore, PC content level in this study was determined as a readout measurement in serum as well as protein extracted from various internal organs including brains, kidneys, pancreases, and livers. In addition, the effect of anti-diabetic drugs, metformin, and p38 MAPK inhibitor (SB203580), as well as the combination of these two drugs, was also determined.

The findings for serum PC levels in this study were similar to other studies for both human and animal models. It has been reported that serum PC levels in diabetic patients are higher than healthy subjects (Almogbel and Rasheed, 2017; Bollineni et al., 2014). In addition, the diabetic animal model of Streptozotocininduced diabetic rats also showed significantly higher serum PC content than non-diabetic rats (Usman et al., 2016). Treatment with metformin showed a reduction in PC content levels in plasma (Usman et al., 2016). Moreover, the treatment with SB203580 could also reduce plasma carbonyl levels in rabbits subjected to the endotoxemia model (Gonzalo et al., 2010). The combination of metformin and SB203580 has never been mentioned in any previous 
studies. Interestingly, the results in this study showed for the first time that metformin and SB203580 could provide a synergistic effect to further reduce serum PC content level. However, this synergistic effect of metformin and SB203580 should be investigated further in larger animal models or human subjects.

Diabetic nephropathy is considered to be the main cause of end-stage renal failure (Alhaider et al., 2011). For PC content in kidneys, previous study has shown that PC content levels in renal tissues of diabetic group were observed to be significantly increased when compared to the control group (Palsamy and Subramanian, 2011). Metformin treatment protected diabetic nephropathy by reduction of oxidative stress, blood glucose, and pro-inflammatory gene expression levels, resulting in improved biochemical changes and restored diabetic nephropathy (Alhaider et al., 2011). The activation of $\mathrm{p} 38$ MAPK regulates ROS generation and inflammation in kidney disease generated in MRL/lpr mouse model of systemic lupus (Jin et al., 2011). Our results showed that SB203580 failed to reduce PC content in the renal tissue of nonobese T2DM. Although previous study has shown that SB203580 could reduce ROS, it also induced inflammation. Furthermore, a concentration of SB203580 greater than $10 \mu \mathrm{M}(1 \mathrm{~mol}=337.43$ g) could enhance pro-inflammatory cytokine, tumor necrosis

(a)

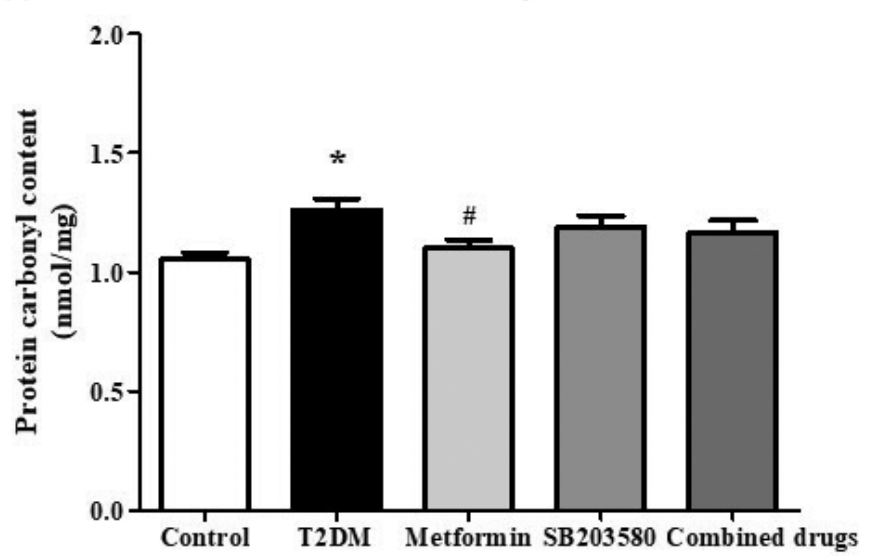

(c)

Liver

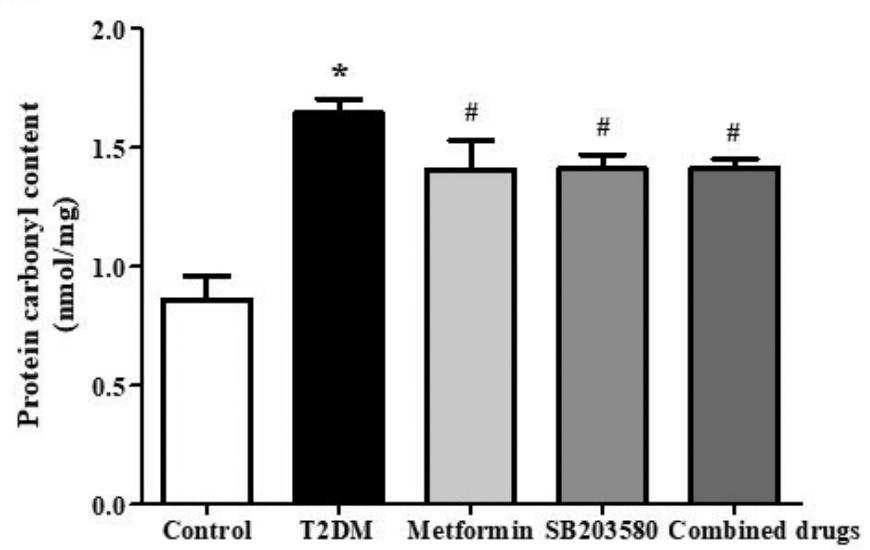

factor- $\alpha(\mathrm{TNF}-\alpha)$ expression, which also induces ROS generation and protein carbonylation (van den Blink et al., 2001). Treatment with metformin together with SB203580 could not provide further reduction of $\mathrm{PC}$ content in the tissue of diabetic kidneys.

Diabetes induced chronic oxidative stress, which is a major mechanism to explain the glucose toxicity in the pancreatic $\beta$ cells, formation of massive ROS within islet of beta cells inadequately normalizes by anti-oxidant due to less production of antioxidant enzymes (Robertson, 2004). It is insufficient to counterbalance the oxidative stress. Therefore, high levels of PC content could be detected in pancreatic tissue. Previous study has demonstrated that metformin protected pancreas by reducing the oxidative stress and cellular damage in streptozotocin-induced diabetic rats (Erejuwa et al., 2010). The reduction of ROS decreased PC content in pancreatic tissue. However, SB203580 treatment in this study could not significantly reduce PC content when compared to the diabetic group. Nonetheless, metformin in combination with SB203580 significantly reduced PC levels compared to the diabetic group. These results might be due to the effect of metformin alone. Therefore, there were no synergistic effects of metformin and

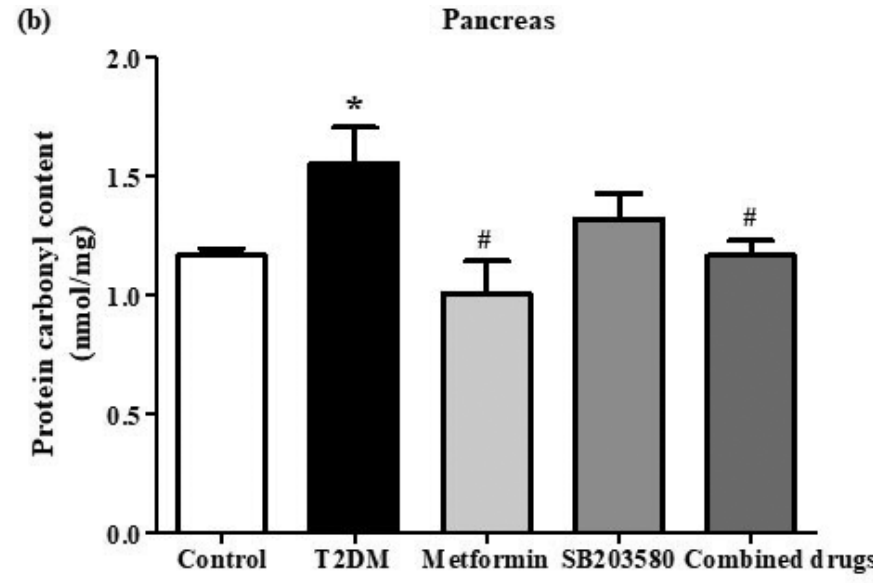

(d)

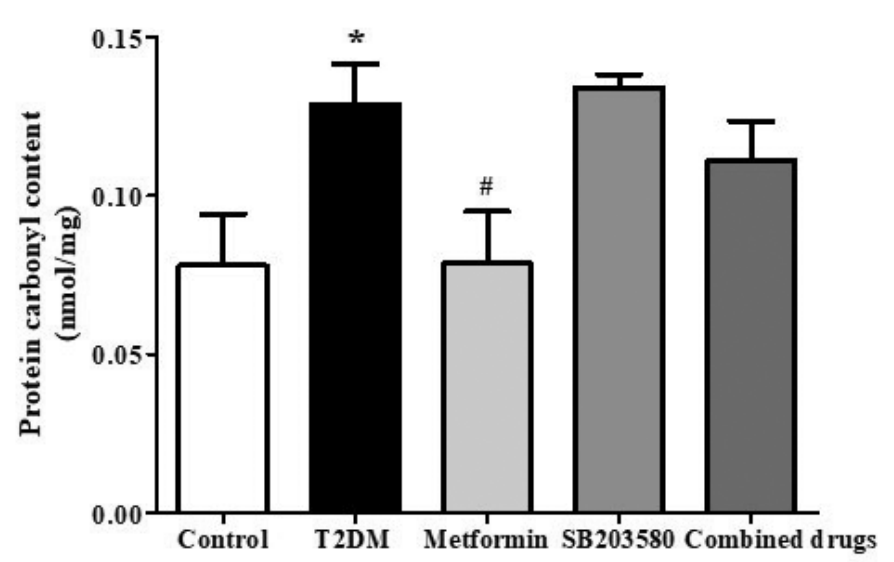

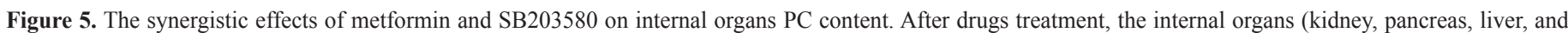

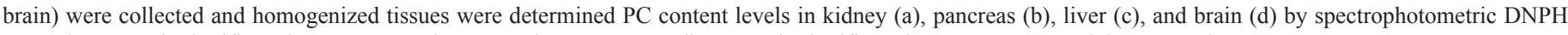
assay. ${ }^{*} p<0.05$ is significant between control group and T2DM group, $\# p<0.05$ is significant between T2DM and drug treated group. 
SB203580 for reducing PC content in pancreatic tissue when compared to metformin mono-therapy.

Hyperglycemia affects lipids, carbohydrates, and protein metabolism, which consequently leads to the development of non-alcoholic fatty liver disease. This could further progress to cirrhosis and hepatocellular carcinomas (Mohamed et al., 2016). It has been reported that hyperglycemia-induced ROS production in isolated hepatocytes of Streptozotocin-induced diabetic models as well as inflammation (Manna et al., 2010; Palsamy et al., 2010) results in high PC levels in hepatic tissue. Metformin primarily targets the liver and provides beneficial effects for patients with chronic liver diseases (Zheng et al., 2015). Treatment with metformin (300 $\mathrm{mg} / \mathrm{kg} /$ day) could reduce blood glucose and ROS production in the liver in Streptozotocininduced diabetic models. This study showed that the metformin could reduce hepatic malondialdehyde, hepatic reduced glutathione, hepatic cytochrome c, and caspase-3 compared to untreated rats (Salman et al., 2013). In addition, pre-treatment with SB203580 could ameliorate ROS generation in the hepatic stem cell line, HepaRG cell line, after Bavachinin challenging (Wang et al., 2018). In this study, the combined therapy of metformin and SB203580 also significantly reduce PC content compared to the T2DM group. However, no significant decrease was observed for metformin or SB203580 mono-therapy in the hepatic tissue of T2DM rats.

Hyperglycemic condition induces oxidative stress while reducing antioxidant levels, resulting in cerebral dysfunction. It is also involved in many neurodegenerative diseases (Muriach et al., 2014). Other T2DM models, such as Zucker diabetic fatty rats (Genetic model), also increased mitochondrial oxidative stress, bioenergetics, and impaired redox homeostasis in the brain tissue that could increase PC accumulation in the brain tissue of non-obese T2DM models (Raza et al., 2015). Previous study has shown that GK rats subjected to cerebral ischemia/reperfusion (I/R) injury by occlusion of the middle cerebral artery expressed higher levels of nitrotyrosine compared to sham operation and could reduce by metformin treatment (Abdelsaid et al., 2015). In this study, mono-therapy with SB203580 or metformin combined with SB203580 showed no change of PC content levels in brain tissue, which may be due to brain sensitivity to oxidative damage (Dugan et al., 1995), leading to high oxygen consumption rates as well as inadequate anti-oxidant enzymes (Muriach et al., 2014). Previous reports have shown that superoxide dismutase and glutathione peroxidase activities in diabetic brains were decreased (Kumar and Menon, 1993; Makar et al., 1995; Muriach et al., 2014). This could explain the results in the current study, which showed no changes in PC content level after SB203580 treatment or combined drugs. Furthermore, less PC content in brain tissue was exhibited than in kidney, liver, and pancreas, which showed the same levels. Previous study has documented that the brain mainly consists of the lipid content (Muriach et al., 2014), meaning there could be lower protein concentration and protein carbonylation in brain tissue. Thus, there are reasons why PC content was shown to be the lowest compared to other organs.

There were some limitations in this study. The determination of PC levels by spectrophotometric DNPH assay is time consuming. Other methods with less assay duration and greater sensitivity, such as enzymatic-linked immunosorbent assay, should be considered for future study of this kind as well as liquid chromatography coupled to tandem mass spectrometry (LC-MS/MS) can provide the high accuracy of PC quantitation and could also provide the ability to identify the type of protein modification, as well as the carbonylated location. In addition, PC content in other vital internal organs which could show diabetic complications, such as the heart, eyes, and vascular tissue, in nonobese T2DM models needs to be investigated. Information from other organs could also provide impactful information concerning the oxidative stress to enhance the risk for diabetic complications. This study showed that combinatorial treatment with metformin and SB203580 for 4 weeks could reduce protein carbonylation only in serum but not in internal organs. Longer duration of combinatory treatment using these drugs could provide more insightful information. Therefore, further study using longer periods of drug treatment should be considered.

\section{CONCLUSION}

To summarize, hyperglycemic condition enhances ROS generation and oxidative stress, which induces protein carbonylation in serum and internal organs, including the kidney, pancreas, liver, and brain. This study showed that the PC content increased in the serum and internal organs of non-obese T2DM model and metformin treatment ameliorated PC content. However, selective p38 MAPK inhibitor could not reduce PC content in the kidney, pancreas, or brain. The combination of metformin and SB203580 could not provide a synergistic effect to further reduce PC content levels in internal organs but could reduce PC content in serum.

\section{ACKNOWLEDGMENTS}

This study was supported by Naresuan University Research (R2559A01 and R2560C138), National Research Council of Thailand and Naresuan University for support Nuttikarn Nokkaew PhD study. We would like to thanks Royal Golden Jubilee Ph.D. Program (No. PHD/0087/2556) and (No. PHD/0125/2558) for Jantira Sanit and Kantapitch Kongpol, respectively. We have special thanks for Centre for Animal Research, Naresuan University for animal facilities and care, and ProofRead4Sure service for English proof reading and editing.

\section{CONFLICT OF INTEREST}

The authors declare no conflicts of interest.

\section{AUTHORS' CONTRIBUTIONS}

Nuttikarn Nokkaew, Podsawee Mongkolpathumrat and Sarawut Kumphune conceived and designed the experiments; Nuttikarn Nokkaew, Siyamon Boontawee, Supanut Ithipruchyabun, Wannapa Plangklang, Jantira Sanit, Punyanuch Adulyaritthikul, and Kantapich Kongpol performed the experiments; Nuttikarn Nokkaew, Podsawee Mongkolpathumrat and Sarawut Kumphune performed data analysis; Sarawut Kumphune contributed reagents/ materials/analysis tools; Nuttikarn Nokkaew and Sarawut Kumphune prepared the manuscript. 


\section{REFERENCES}

Abdelsaid M, Prakash R, Li W, Coucha M, Hafez S, Johnson MH, Fagan SC, Ergul A. Metformin treatment in the period after stroke prevents nitrative stress and restores angiogenic signaling in the brain in diabetes. Diabetes, 2015; 64:1804-17.

Alhaider AA, Korashy HM, Sayed-Ahmed MM, Mobark M, Kfoury H, Mansour MA. Metformin attenuates streptozotocin-induced diabetic nephropathy in rats through modulation of oxidative stress genes expression. Chem Biol Interact, 2011; 192:233-42.

Almogbel E, Rasheed N. Protein mediated oxidative stress in patients with diabetes and its associated neuropathy: correlation with protein carbonylation and disease activity markers. J Clin Diagn Res, 2017; 11:BC21-5.

Boffetta P, McLerran D, Chen Y, Inoue M, Sinha R, He J, Gupta PC, Tsugane S, Irie F, Tamakoshi A, Gao Y-T, Shu X-O, Wang R, Tsuji I, Kuriyama S, Matsuo K, Satoh H, Chen C-J, Yuan J-M, Yoo K-Y, Ahsan H, Pan W-H, Gu D, Pednekar MS, Sasazuki S, Sairenchi T, Yang G, Xiang Y-B, Nagai M, Tanaka H, Nishino Y, You S-L, Koh W-P, Park SK, Shen C-Y, Thornquist M, Kang D, Rolland B, Feng Z, Zheng W, Potter JD. Body mass index and diabetes in Asia: a cross-sectional pooled analysis of 900,000 individuals in the Asia Cohort Consortium. PLoS One, 2011; 6:e19930.

Bollineni RC, Fedorova M, Bluher M, Hoffmann R. Carbonylated plasma proteins as potential biomarkers of obesity induced type 2 diabetes mellitus. J Proteome Res, 2014; 13:5081-93.

Carlson CJ, Koterski S, Sciotti RJ, Poccard GB, Rondinone CM. Enhanced basal activation of mitogen-activated protein kinases in adipocytes from type 2 diabetes. Potential role of $\mathrm{p} 38$ in the downregulation of GLUT4 expression. Diabetes, 2003; 52:634-41.

DeFronzo RA, Ferrannini E, Groop L, Henry RR, Herman WH, Holst JJ, Hu FB, Kahn CR, Raz I, Shulman GI, Simonson DC, Testa MA, Weiss R. Type 2 diabetes mellitus. Nat Rev Dis Primers, 2015; 1:15019.

Dugan LL, Sensi SL, Canzoniero LM, Handran SD, Rothman SM, Lin TS, Goldberg MP, Choi DW. Mitochondrial production of reactive oxygen species in cortical neurons following exposure to N-methyl-Daspartate. J Neurosci, 1995; 15:6377-88.

Erejuwa OO, Sulaiman SA, Wahab MS, Salam SK, Salleh MS, Gurtu S. Antioxidant protective effect of glibenclamide and metformin in combination with honey in pancreas of streptozotocin-induced diabetic rats. Int J Mol Sci, 2010; 11:2056-66.

Evans JL, Goldfine ID, Maddux BA, Grodsky GM. Oxidative stress and stress-activated signaling pathways: a unifying hypothesis of type 2 diabetes. Endocr Rev, 2002; 23:599-622.

Fedorova M, Bollineni RC, Hoffmann R. Protein carbonylation as a major hallmark of oxidative damage: update of analytical strategies. Mass Spectrom Rev, 2014; 33:79-97.

Gonzalo S, Grasa L, Arruebo M, Plaza Má, Murillo M. Inhibition of p38 MAPK improves intestinal disturbances and oxidative stress induced in a rabbit endotoxemia model. J Neurogastroenterol Motil, 2010; 22:564-e123.

Jin N, Wang Q, Zhang X, Jiang D, Cheng H, Zhu K. The selective p38 mitogen-activated protein kinase inhibitor, SB203580, improves renal disease in MRL/lpr mouse model of systemic lupus. Int Immunopharmacol, 2011; 11:1319-26.

Kumar JS, Menon VP. Effect of diabetes on levels of lipid peroxides and glycolipids in rat brain. Metabolism, 1993; 42:1435-9.

Kumphune S, Chattipakorn S, Chattipakorn N. Role of p38 inhibition in cardiac ischemia/reperfusion injury. Eur J Clin Pharmacol, 2012; 68:513-24.

Makar TK, Rimpel-Lamhaouar K, Abraham DG, Gokhale VS, Cooper AJL. Antioxidant defense systems in the brains of type II diabetic mice. J Neurochem, 1995; 65:287-91.

Maneewong K, Mekrungruangwong T, Luangaram S, Thongsri T, Kumphune S. Combinatorial determination of Ischemia modified albumin and protein carbonyl in the diagnosis of nonST-elevation myocardial infarction. Indian J Clin Biochem, 2011; 26:389-95.
Manna P, Das J, Ghosh J, Sil PC. Contribution of type 1 diabetes to rat liver dysfunction and cellular damage via activation of NOS, PARP, I $\kappa \mathrm{B} \alpha / \mathrm{NF}-\kappa \mathrm{B}$, MAPKs, and mitochondria-dependent pathways: Prophylactic role of arjunolic acid. Free Radic Biol Med, 2010; 48:1465-84.

Mohamed J, Nazratun Nafizah AH, Zariyantey AH, Budin SB Mechanisms of diabetes-induced liver damage: the role of oxidative stress and inflammation. Sultan Qaboos Univ Med J, 2016; 16:e132-41.

Muriach M, Flores-Bellver M, Romero FJ, Barcia JM. Diabetes and the brain: oxidative stress, inflammation, and autophagy. Oxid Med Cell Longev, 2014; 2014:9.

Nokkaew N, Mongkolpathumrat P, Junsiri R, Jindaluang S, Tualamun N, Manphatthanakan N, Saleesee N, Intasang M, Sanit J, Adulyaritthikul P, Kongpol K, Kumphune S, Nernpermpisooth N. p38 MAPK inhibitor (SB203580) and metformin reduces aortic protein carbonyl and inflammation in non-obese type 2 diabetic rats. Indian J Clin Biochem, $2019 ; 1-7$.

Palsamy P, Sivakumar S, Subramanian S. Resveratrol attenuates hyperglycemia-mediated oxidative stress, proinflammatory cytokines and protects hepatocytes ultrastructure in streptozotocin-nicotinamideinduced experimental diabetic rats. Chem Biol Interact, 2010; 186 $200-10$.

Palsamy P, Subramanian S. Resveratrol protects diabetic kidney by attenuating hyperglycemia-mediated oxidative stress and renal inflammatory cytokines via Nrf2-Keap1 signaling. Biochim Biophys Acta, 2011; 1812:719-31.

Paneni F, Beckman JA, Creager MA, Cosentino F. Diabetes and vascular disease: pathophysiology, clinical consequences, and medical therapy: part I. Eur Heart J, 2013; 34:2436-43.

Raza H, John A, Howarth FC. Increased oxidative stress and mitochondrial dysfunction in zucker diabetic rat liver and brain. Cell Physiol Biochem, 2015; 35:1241-51.

Robertson RP. Chronic oxidative stress as a central mechanism for glucose toxicity in pancreatic islet beta cells in diabetes. J Biol Chem, 2004; 279:42351-4.

Salman ZK, Refaat R, Selima E, El Sarha A, Ismail MA. The combined effect of metformin and L-cysteine on inflammation, oxidative stress and insulin resistance in streptozotocin-induced type 2 diabetes in rats. Eur J Pharmacol, 2013; 714:448-55.

Sarkar P, Kar K, Mondal MC, Chakraborty I, Kar M. Elevated level of carbonyl compounds correlates with insulin resistance in type 2 diabetes. Ann Acad Med Singapore, 2010; 39:909.

Sasaki S, Inoguchi T. The role of oxidative stress in the pathogenesis of diabetic vascular complications. Diabetes Obes Metab, $2012 ; 36: 255-61$.

Son SM. Reactive oxygen and nitrogen species in pathogenesis of vascular complications of diabetes. Diabetes Metab J, 2012; 36:190-8

Suzuki YJ, Carini M, Butterfield DA. Protein carbonylation. Antioxid Redox Signal, 2010; 12:323-5.

Tang Z, Fang Z, Huang W, Liu Z, Chen Y, Li Z, Zhu T, Wang Q, Simpson S, Taylor BV, Lin R. Non-obese diabetes and its associated factors in an underdeveloped area of South China, Guangxi. Int J Environ Res Public Health, 2016; 13:976.

Usman UZ, Bakar ABA, Mohamed M. Metformin reduces oxidative stress status and improves plasma insulin level in streptozotocininduced diabetic rats. JPANS, 2016; 6:120-5.

van den Blink B, Juffermans NP, ten Hove T, Schultz MJ, van Deventer SJ, van der Poll T, Peppelenbosch MP. p38 mitogenactivated protein kinase inhibition increases cytokine release by macrophages in vitro and during infection in vivo. J Immunol, 2001; 166:582-7.

Wang S, Wang M, Wang M, Tian Y, Sun X, Sun G, Sun X. Bavachinin induces oxidative damage in HepaRG cells through p38/JNK MAPK pathways. Toxins (Basel), 2018; 10:154. 
Wilcox G. Insulin and insulin resistance. Clin Biochem Rev, $2005 ; 26: 19-39$.

Yamagishi S-I, Nakamuraa K, Matsuia T, Inoueb H. Diabetic vascular complication. Antioxidants, 2006; 49.

Zheng J, Woo S-L, Hu X, Botchlett R, Chen L, Huo Y, Wu C. Metformin and metabolic diseases: a focus on hepatic aspects. Front Med (Lausanne), 2015; 9:173-86.
How to cite this article:

Nokkaew N, Sanit J, Mongkolpathumrat P, Boontawee S, Ithipruchyabun S, Plangklang W, Adulyaritthikul P, Kongpol K, Kumphune S. Anti-diabetic drug, metformin, and the p38 inhibitor (SB203580) reduces internal organs oxidative stress in non-obese type 2 diabetic rats. J Appl Pharm Sci, 2019; 9(05):012-020. 